\title{
molecules
}

ISSN 1420-3049

http://www.mdpi.org

Review

\section{Polyalkoxy Nitrones as Chiral Building Blocks in Asymmetric Synthesis}

\author{
Pedro Merino* and Tomás Tejero \\ Departamento de Quimica Organica, Universidad de Zaragoza, E-50009 Zaragoza, Aragon, Spain \\ Fax: +34 976 762075, E-mail: pmerino@posta.unizar.es \\ htttp://wzar.unizar.es/acad/fac/cie/quiorg/asimetrica/mtm.html \\ *Author to whom correspondence should be addressed.
}

Received: 23 December 1998 / Accepted: 20 March 1999 / Received in revised form: 29 May 1999 / Published: 4 June 1999

\begin{abstract}
Optically active nitrones derived from both aldoses and dialdoses add metallated heterocycles in a stereocontrolled way depending on the nature of the Lewis acid used as a precomplexing agent of the nitrone. Further elaborations of the resulting hydroxylamines lead to the development of new synthetic methodologies for the preparation of polyalkoxy $\alpha$-amino aldehydes and $\alpha$-amino acids. These compounds can be used as key advanced intermediates in the synthesis of a wide range of natural products and derivatives including amino sugars, aza sugars, and complex nucleosides.
\end{abstract}

Keywords: Nitrones, hydroxylamines, carbohydrates, aminoacids, aminoaldehydes.

\section{Introduction}

The growing demand for enantiomerically pure compounds has led chemists to investigate a variety of approaches to such a sort of molecules. One method that has been widely recognized lies in the use of carbohydrates for preparing suitable chiral building blocks bearing, in most cases, several oxygenated functions in different oxidation states [1].

(C) 1999 by the authors. Reproduction of this article, by any means, is permitted for noncommercial purposes. 
A considerable part of the synthetic applications of carbohydrate-derived chiral building blocks is connected with their use as precursors of nitrogenated compounds such as amino sugars, alkaloids or amino acids [2]. Unfortunately, the development of nitrogenated building blocks prepared from carbohydrates has proceeded at a slower pace and has not reached the degree of complexity of its oxygenated counterparts. However, for the preparation of a variety of optically active nitrogenated compounds it is possible to introduce a nitrogen functionality at an earlier stage in order to prepare nitrogenated chiral building blocks of wide applicability. In this context the spectrum of application of carbohydrate-derived nitrones (polyalkoxy nitrones) is very broad and the synthetic importance of these compounds is still rapidly developing.

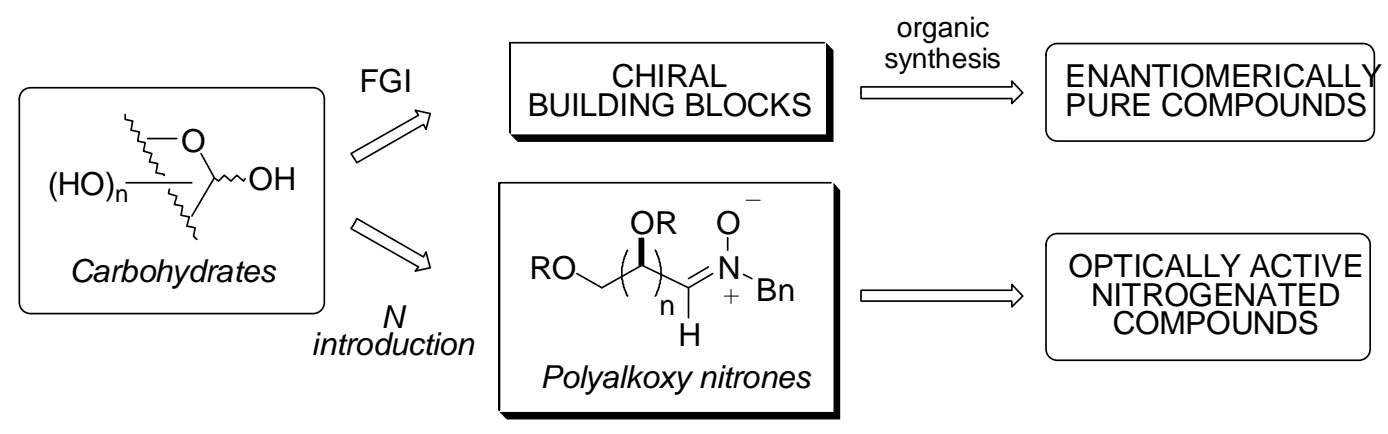

Polyalkoxy nitrones have been used as 1,3-dipoles in cycloaddition reactions during the synthesis of optically active nitrogenated compounds [3]. Since the 1,3-dipolar chemistry of nitrones has been widely reviewed [4], the main focus of this review will be limited to recent studies carried out in our laboratories at the University of Zaragoza on the reactivity of the title compounds as electrophiles in nucleophilic additions and application of the resulting hydroxylamines in organic synthesis.

\section{Synthesis}

Several methods for preparing nitrones have been developed. These include oxidation of hydroxylamines [5], imines [6] and amines [7], alkylation of oximes [8] and condensation between a carbonyl compound and a N-substituted hydroxylamine[9]. 


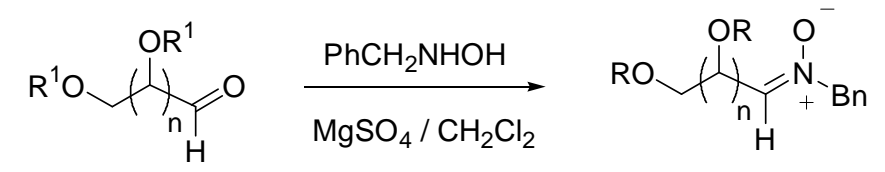

1<smiles>CC1(C)CC(/C=[N+](\[O-])Br)CO1</smiles>

2

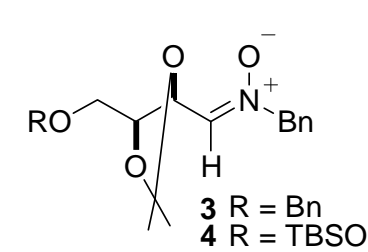

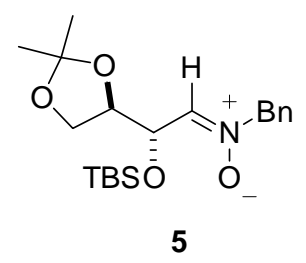

2-14<smiles>[O-][N+](=CCc1ccccc1)C(O)C1OCCO1</smiles>

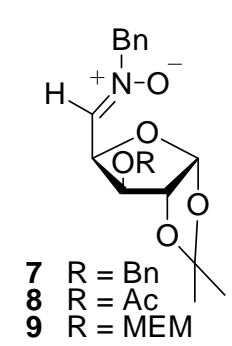

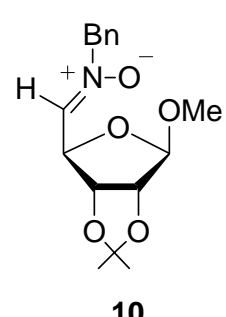

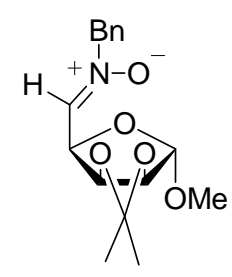

11

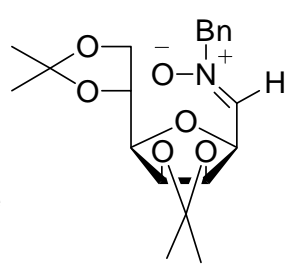

12

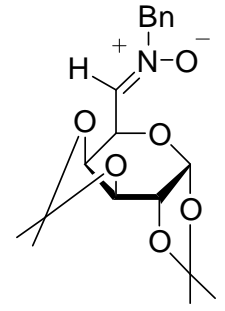

13

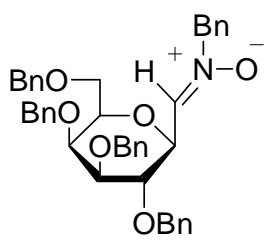

14

Scheme 1.

Among these methods the later is more appropriate for preparing polyalkoxy nitrones since a variety of polyalkoxy aldehydes are easily accessible from the carbohydrate-based chiral pool. Thus, the reaction of polyalkoxy aldehydes with N-benzyl hydroxylamine, in the presence of magnesium sulfate as a drying agent led to the polyalkoxy nitrones illustrated in Scheme 1, as the result of a dehydrocondensation process [10]. The yields are good and in all cases only the Z-isomers were obtained as could be demonstrated by NMR spectroscopy (NOE experiments).

\section{Reactivity}

Polyalkoxy nitrones show a rich variety of nucleophilic additions, as might be expected for the electrophilic character of the nitrone functionality. For instance, asymmetric nucleophilic additions of metalated heterocycles provided the corresponding hydroxylamines with high syn diastereoselectivity. Alternatively, the reaction with nitrones previously treated with 1.0 equiv of $\mathrm{Et}_{2} \mathrm{AlCl}$ led preferentially to the anti isomers. In consequence a complete stereocontrol could be achieved as it has been demonstrated for thiazole [11], furan [12], imidazole [12], thiophene[13] and their benzoderivatives [13] (Scheme 2). 


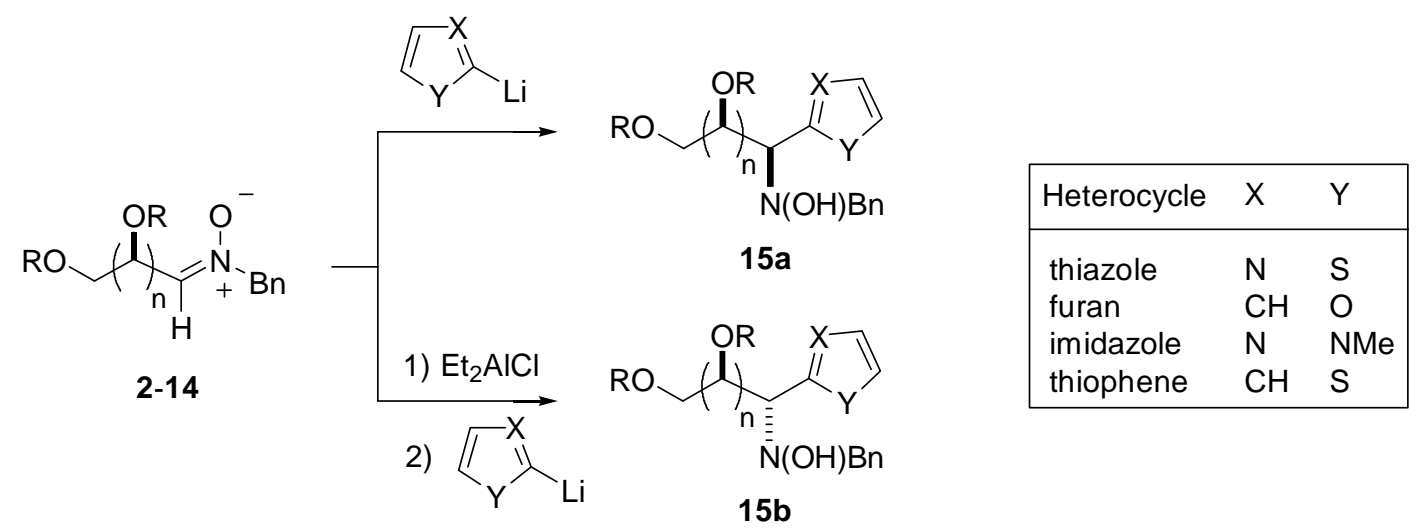

Scheme 2.

In the case of thiazole and furan, the synthetic equivalences of these heterocyclic rings with the formyl and carboxyl groups, respectively, were exploited for developing new synthetic methodologies. The conversion of (hydroxyaminomethyl)thiazoles $\mathbf{1 5}$ to the protected (aminomethyl)thiazoles $\mathbf{1 6}$ could be done by a two-step process consisting of concomitant deoxygenation and debenzylation with titanium (III) chloride and further reaction with di-tert-butyl dicarbonate in dioxane [14] (Scheme 3). Finally, transformation of the thiazole ring into a formyl group according to the described protocol [15] furnished $\alpha$-amino aldehydes 17. Similarly, (hydroxyaminomethyl)furans $\mathbf{1 8}$ were transformed into protected (aminomethylfurans) 19. Oxidation of the furan ring with ruthenium (III) chloride (or ruthenium (II) oxide) in the presence of sodium periodate, according to the literature [16], afforded $\beta$ hydroxy- $\alpha$-amino acids 20 (Scheme 3) [17]. These reaction sequences allowed the preparation of novel chiral (aminomethyl)- and (hydroxyaminomethyl) heterocycles, whose absolute configuration could be assigned by circular dichroism on the basis of new sector rules developed in our laboratory for both thiazole [18] and furan [19] derivatives. In other cases, X-ray crystallography of those products, or some other derivative, was used as a definitive corroboration [20].

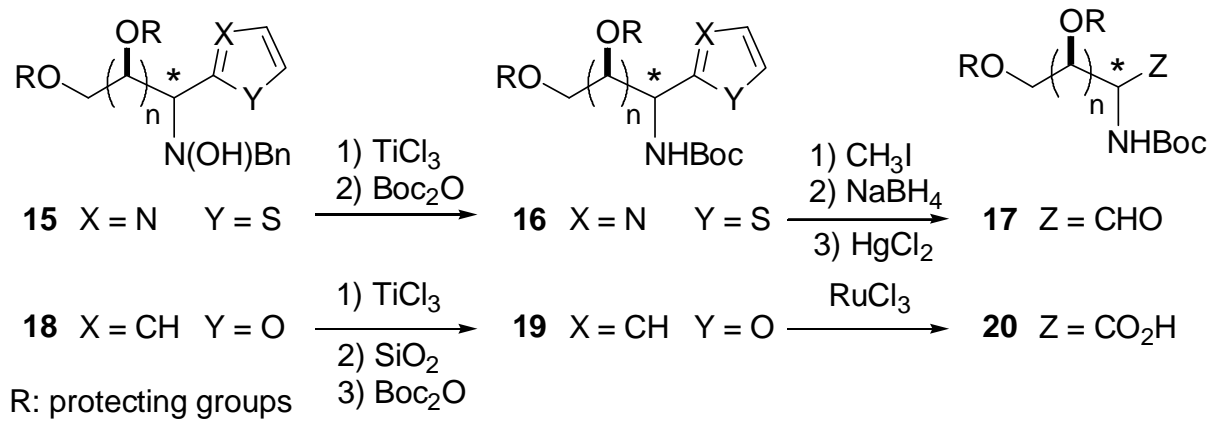

Scheme 3.

Since the starting nitrones (precursors of hydroxylamines $\mathbf{1 5}$ and 18) were prepared from the corresponding aldehydes, the overall processes outlined in Scheme 3 can be considered as 
stereoselective homologations with incorporation of an amino functionality into the newly generated asymmetric center. We referred to these transformations as thiazole-based aminohomologation (TBAH) [14] and furan-based aminohomologation (FBAH) [17], respectively (Scheme 4).

AMINOHOMOLOGATIONS
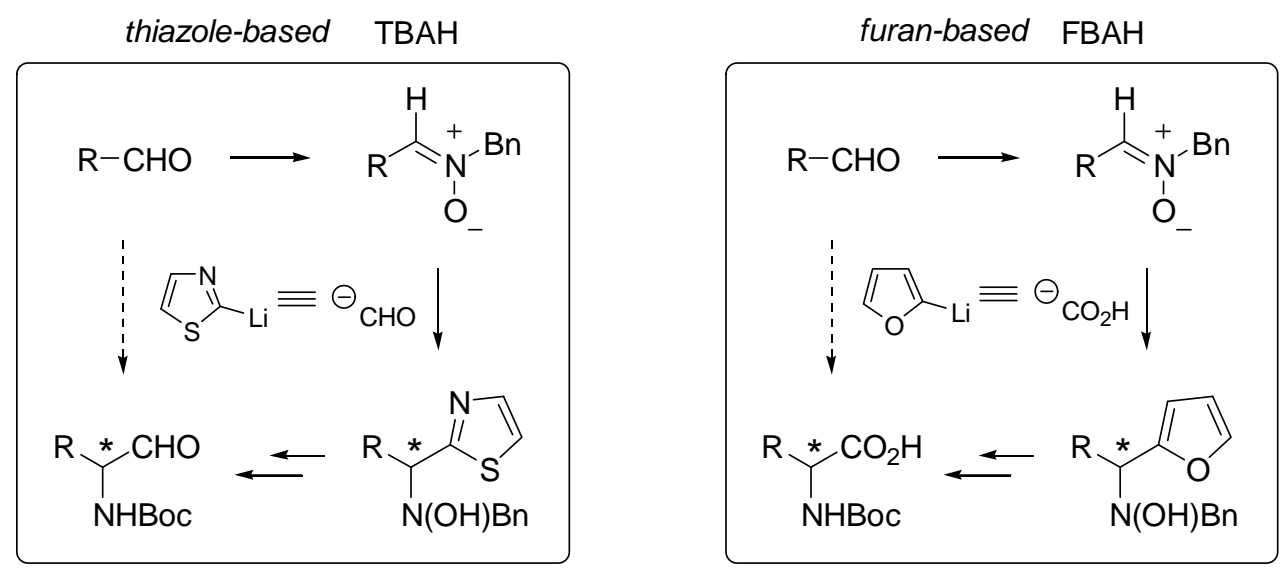

\section{Scheme 4.}

The reactivity of polyalkoxy nitrones with hetaryl nucleophiles of synthetic utility [21] (such as furan and thiazole) made possible the total syntheses of several natural products of interest. Both chemical transformations prior to the cleavage of the heterocyclic system and further elaborations of the prepared key intermediates ( $\alpha$-amino aldehydes and $\alpha$-amino acids) allowed the total synthesis of amino sugars, aza sugars or complex nucleosides.

The arabinose-derived nitrone $\mathbf{6}$, obtained from the corresponding aldehyde, was made to react with 2-lithiothiazole to furnish the corresponding hydroxylamine which was converted into $\alpha$-amino aldehyde 21 following the thiazole-base aminohomologation protocol, TBAH, described above (Scheme 5). Deprotection of the acetonide moiety afforded the aminosugar N-acetyl-D-mannosamine $22[14,22]$.

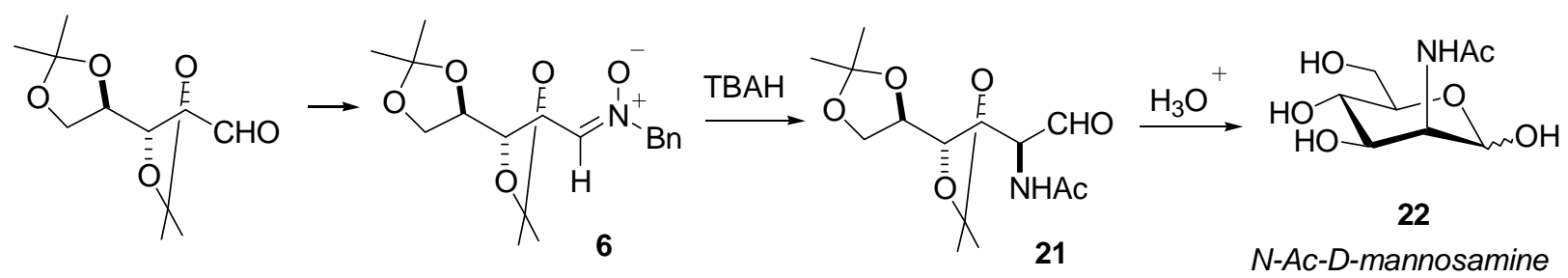

\section{Scheme 5.}

The stereocontrolled aminohomologation of aldehyde $\mathbf{2 3}$ led to epimeric $\alpha$-amino aldehydes $\mathbf{2 4}$ and 24, advanced intermediates in synthesis of destomic acid and lincosamine, respectively (Scheme 6) [23]. 


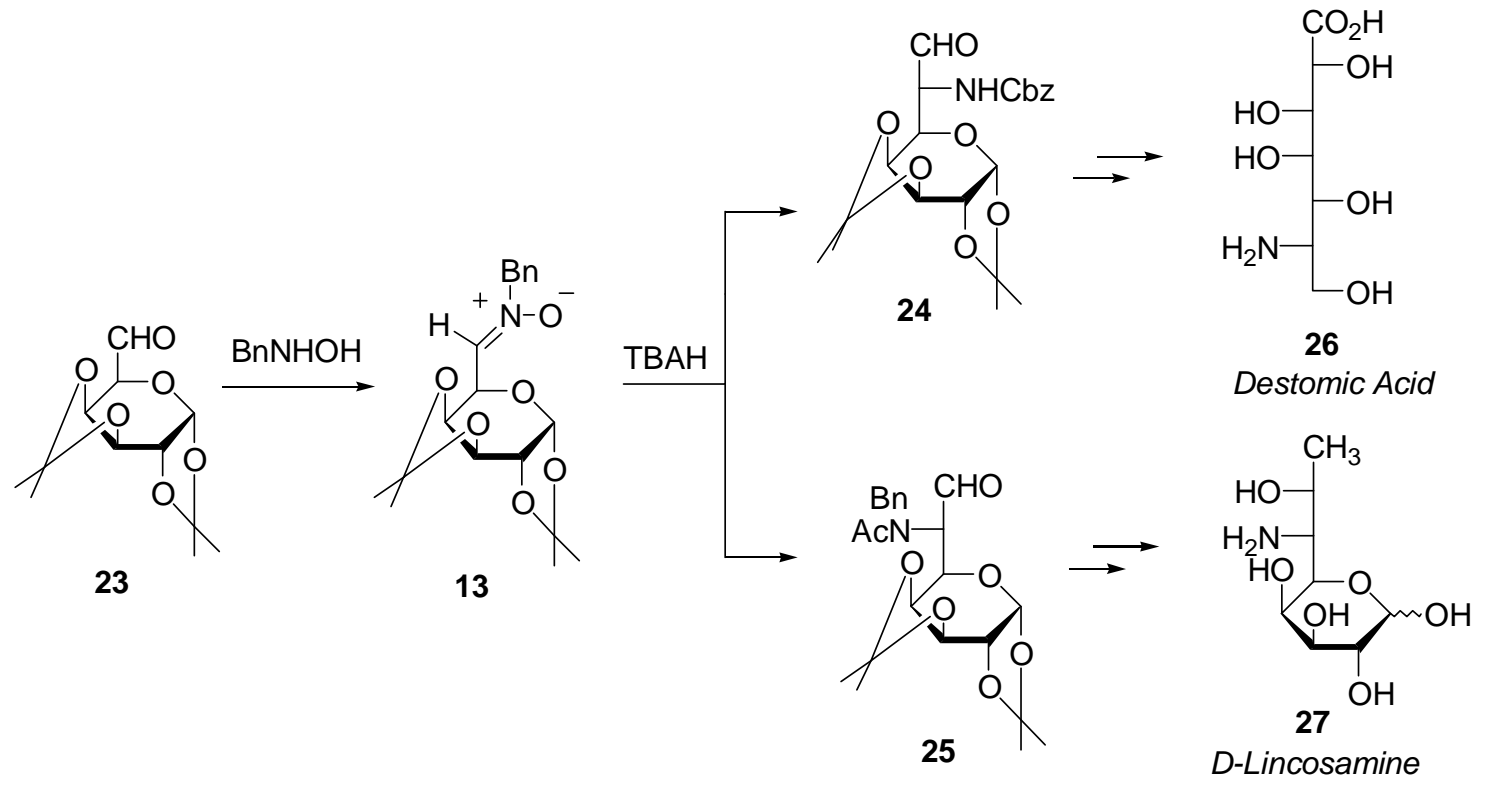

Scheme 6.

Similarly, aldehyde $\mathbf{2 8}$ was subjected to the same methodology to furnish $\alpha$-aminoaldehyde 29 which was further transformed into the aza sugar D-nojirimycin (Scheme 7) [14].
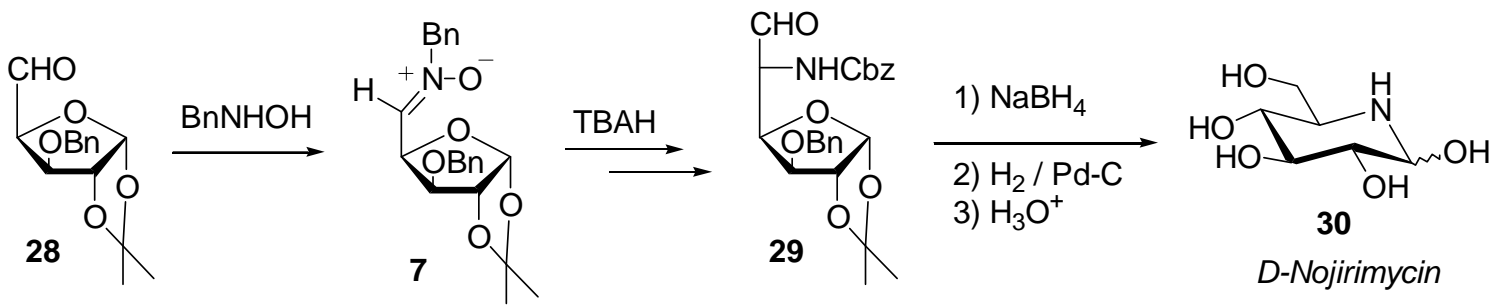

\section{Scheme 7.}

The above nitrone-thiazole methodology was also applied for the synthesis of novel anomeric Cglycosyl $\alpha$-amino acids by oxidation of the corresponding $\alpha$-amino aldehydes with $\mathrm{NaClO}_{2}$ in aqueous $\mathrm{NaH}_{2} \mathrm{PO}_{4}$ [24].

In addition to the above mentioned synthesis of $\beta$-hydroxy- $\alpha$-amino acids through the reaction of 2 furyllithium with aldose-derived nitrones outlined in Scheme 3, the furan-based methodology was also utilized for preparing both glycosyl $\alpha$-amino acids and their N-hydroxy derivatives (Scheme 8) [24]. 


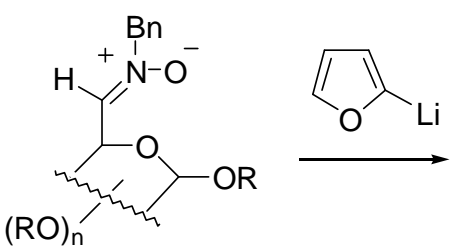

7-14

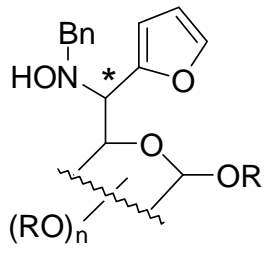

31

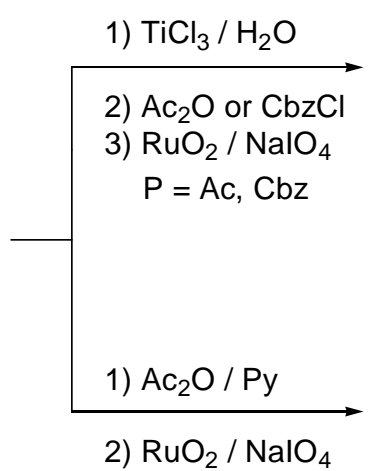

32

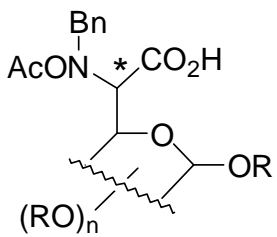

33

\section{Scheme 8.}

The FBAH methodology was used for the total synthesis of Polyoxin $\mathbf{J}$ 34, a peptidyl nucleoside antibiotic of interest as an inhibitor of chitin biosynthesis. The two constituent fragments of Polyoxin J (polyoxamic acid 35 and thymine Polyoxin C 36) were synthesized in our laboratory by aminohomologation of the corresponding polyalkoxy aldehydes $\mathbf{3 7}$ and $\mathbf{3 8}$ (Scheme 9) [25].<smiles>C=CC(=O)C(N)C(O)C(O)COC(N)=O</smiles>

35

Polyoxamic acid<smiles>Cc1cn(C2O[C@H]3C(O)[C@H](O2)C(N)(C(=O)O)[C@@H]3O)c(=O)[nH]c1=O</smiles>

36

Thymine Polyoxin C<smiles>CC(C)OC(COBr)C(O)C=O</smiles>

37<smiles>Cc1cn(C2OC(C(=O)NC(C(=O)O)C(N)C(O)C(O)C(O)COC(N)=O)C(O)C2O)c(=O)[nH]c1=O</smiles>

Polyoxin J, 34<smiles>C=CCC</smiles>

Scheme 9.

The total synthesis of Polyoxin $\mathrm{J}$ is outlined in Scheme 10. Application of our method to the Lthreose-derived aldehyde $\mathbf{3 9}$ afforded the protected polyoxamic acid $\mathbf{4 0}$ in a $25.8 \%$ overall yield from aldehyde 39 (7 steps) [26]. 


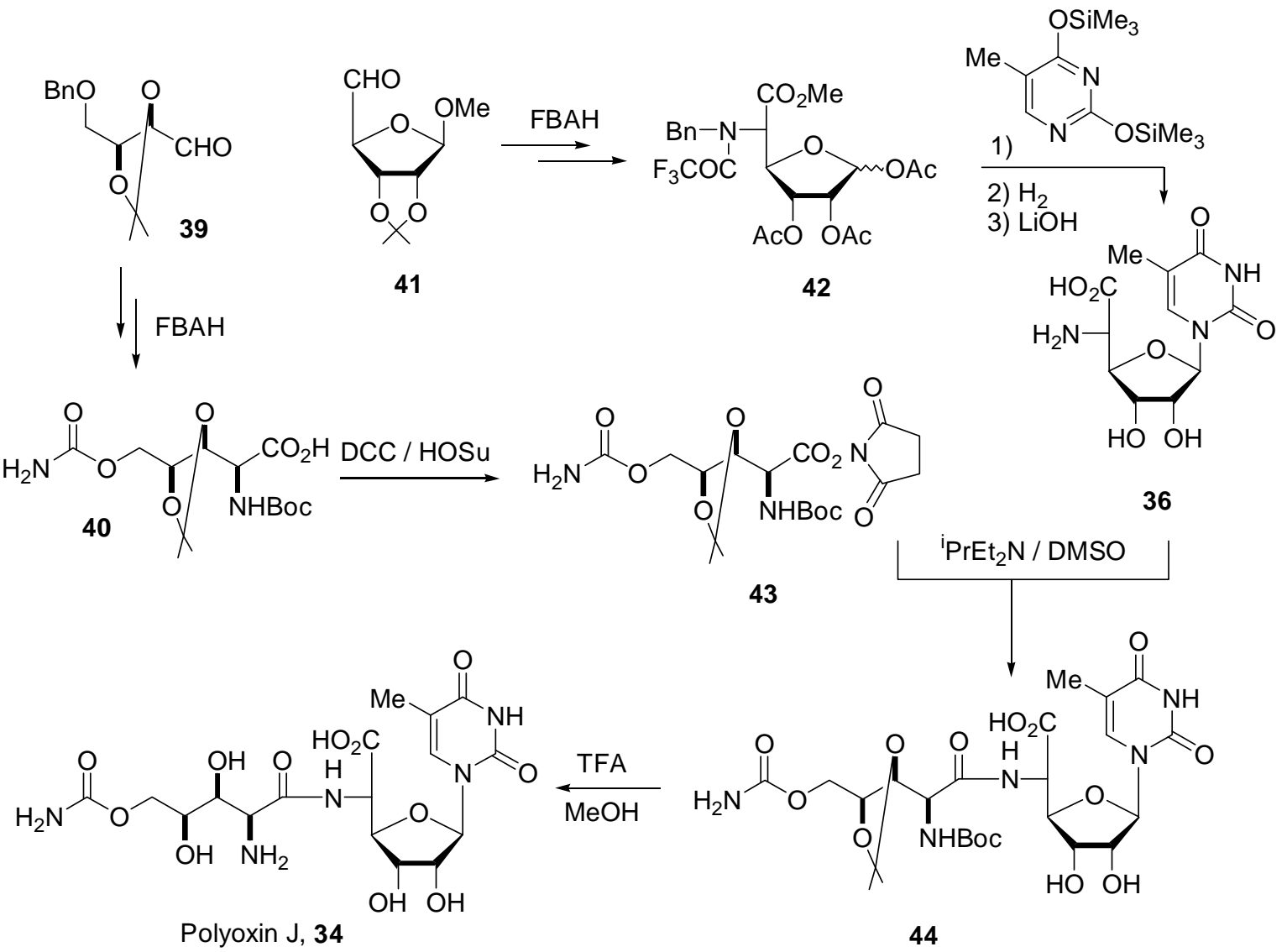

Scheme 10.

Several synthetic approaches to the thymine polyoxin C 36 were envisioned [27], the best of them being that illustrated in Scheme 10. In this case, the $\mathrm{FBAH}$ methodology using $\mathrm{Et}_{2} \mathrm{AlCl}$ as a precomplexing agent led to the glycosyl $\alpha$-amino acid $\mathbf{4 2}$ with the required stereochemistry. Glycosylation with 2,4-bis(trimethylsilyl)thymine of $\mathbf{4 2}$ gave the nucleoside amino acid $\mathbf{4 3}$. Complete deprotection of this derivative by reductive and hydrolytic methods furnished natural thymine polyoxin C 36 in a 9.6\% overall yield from aldehyde 41 (10 steps) [26]. The final coupling between 36 and 40 was performed by the N,N-dicyclohexylcarbodiimide N-hydroxysuccinimide (DCC / HOSu) active ester method. Thus protected polyoxamic acid $\mathbf{4 0}$ was converted into active ester $\mathbf{4 3}$ which was then treated with thymine polyoxin C 36 to afford the dipeptide 44 . Finally, deprotection of 45 by treatment with aqueous trifluoroacetic acid gave, after purification by column chromatography, Polyoxin $\mathrm{J}$ in $46 \%$ yield $[25,26] .{ }^{25,26}$

\section{Concluding Remarks}

As discussed, our heterocycle-nitrone methodologies were appropriate for the development of highly efficient stereoselective synthetic routes to a variety of nitrogenated compounds of interest. For 
further application of polyalkoxy nitrones our attention is now focused in the use of different nucleophiles which allow access to more elaborated compounds. Thus there is still great room for development of effective synthetic methodologies based on nucleophilic addition to polyalkoxy nitrones.

Acknowledgements: The work from our laboratories at the University of Zaragoza (Spain) reviewed herein has been the result of a gratifying collaboration with a number of doctoral students and colleagues whose names appear in the list of references. Financial support for this research come entirely from the Spanish Ministry of Education (MEC, DGICYT, Madrid, Spain. Projects PM92-0253 and PB94-0598).

\section{References and Notes}

1. For reviews see: (a) Inch, T.D. Tetrahedron 1984, 40, 3161-3213. (b) Dueholm, K.L.; Pedersen, E.B. Synthesis 1992, 1-22. (c) Ferrier, R.J.; Middleton, S. Chem. Rev. 1993, 93, 2779-2831. (d) Casiraghi, G.; Zanardi, F.; Rassu, G.; Spanu, P. Chem. Rev. 1995, 95, 1677-1716. (e) Knapp. S. Chem. Rev. 1995, 95, 1859-1876. (f) Hultin, P.G.; Earle, M.A.; Sudharshan, M. Tetrahedron 1997, 53, 14823-14870.

2. For reviews see: (a) Fleet, G.W.J. Chem. Brit 1989, 287-292. (b) Cintas, P. Tetrahedron 1991, 47, 6079-6111. (c) Kaluza, Z.; Abramski, W.; Chmielewski, M. Ind. J. Chem. 1994, 33B, 913-940. (d) Martinez-Grau, A.; Marco-Contelles, J. Chem. Soc. Rev. 1998, 27, 155-162.

3. (a) DeShong, P.; Leginus, J.M. J. Am. Chem. Soc. 1983, 105, 1686-1688. (b) DeShong, P.; Dicken, C.M.; Leginus, J.M.; Whittle, R.R. J. Am. Chem. Soc. 1984, 106, 5598-5602. (c) Vasella, A.; Voeffray, R. Helv. Chim. Acta 1982, 65, 1134-1144. (d) Vasella, A.; Voeffray, R.; Pless, J.; Huguenin, R. Helv. Chim. Acta 1983, 66, 11241-1252. (e) DeShong, P.; Li, W.; Kennington, J.W.; Ammon, H.L. J. Org. Chem. 1991, 56, 1364-1373. (f) Iida, H.; Kasahara, K.; Kibayashi, C. J. Am. Chem. Soc. 1986, 108, 4647-4648. (g) Iida, H.; Kasahara, K.; Kibayashi, C. J. Org. Chem. 1989, 54, 2225-2233. (h) Herczeg, P.; Kovacs, I.; Szilagyi, L.; Varga, T.; Dinya, Z.; Sztaricskai, F. Tetrahedron Lett. 1993, 34, 1211-1214. (i) Cordero, F.M.; Cicchi, S.; Goti, A.; Brandi, A. tetrahedron Lett. 1994, 35, 949-952.

4. (a) Tufariello, J.J. In 1,3-Dipolar Cycloaddition Chemistry Padwa, A. (Ed.), Wiley, New York, 1984, vol. 2, pp. 83-168. (b) Padwa, A. In Comprehensive Organic Synthesis Trost, B.M. (Ed.), Pergamon, Oxford, 1991, vol. 4, chap. 4.9. and references cited therein. (c) Frederickson, M. Tetrahedron 1997, 53, 403-425.

5. (a) Tuffariello, J.J.; Lee, G.E. J. Am. Chem. Soc. 1980, 102, 373-374. (b) Aurich, H.G.; Schmidt, M.; Schwerzel, T. Chem. Ber. 1985, 118, 1086-1104.

6. (a) Christensen, D.; Jorgensen, K.A. J. Org. Chem. 1989, 54, 126-131. (b) Abou-Gharbia, M.A.; Joullie, M.M. Org. Prep. Proc. Int. 1979, 11, 95-96. 
7. Murahashi, S.-I.; Mitsui, H.; Shiota, T.; Tsuda, T.; Watanabe, S. J. Org. Chem. 1990, 55, 17361744.

8. Zschiesche, R.; Reissig, H.V. Tetrahedron Lett. 1988, 29, 1685-1686.

9. (a) Franco, S.; Merchan, F.L.; Merino, P.; Tejero, T. Synth. Commun. 1995, 25, 2275-2284. (b) Dondoni, A.; Franco, S.; Junquera, F.; Merchan, F.L.; Merino, P.; Tejero, T. Synth. Commun. 1994, 24, 2537-2550.

10. Franco, S. Ph.D. Thesis. University of Zaragoza (Spain). 1994. See also ref. 9.

11. Dondoni, A.; Franco, S.; Merchan, F.L.; Merino, P.; Tejero, T. Tetrahedron Lett. 1993, 34, 54755478.

12. Dondoni, A.; Franco, S.; Merchan, F.L.; Merino, P.; Tejero, T. Tetrahedron Lett. 1993, 34, 54795482.

13. Merino, P.; Franco, S.; Martinez, I.; Merchan, F.L.; Tejero, T. Electronic Conference on Heterocyclic Chemistry (ECHET98). Internet: http://www.ch.ic.ac.uk/ectoc/echet98/.

14. Dondoni, A.; Junquera, F.; Franco, S.; Merchan, F.L.; Merino, P.; Tejero, T.; Bertolasi, V. Chem. Eur. J. 1995, 1, 505-520.

15. Dondoni, A.; Merino, P. Org. Synth. 72, 21-31.

16. (a) Mukaiyama, T.; Tsuzuki, R.; Kato, J. Chem. Lett. 1985, 837-840. (b) Danishefksy, S.J.; DeNinno, M.P.; Chen, S. J. Am. Chem. Soc. 1988, 110, 3929-3940. (c) Marshall, J.A.; Luke, G.P. J. Org. Chem. 1993, 58, 6229-6234.

17. Dondoni, A.; Junquera, F.; Merchan, F.L.; Merino, P.; Tejero, T. Synthesis 1994, 1450-1456.

18. Merchan, F.L.; Merino, P.; Rojo, I.; Tejero, T.; Dondoni, A. Tetrahedron: Asymmetry 1995, 6, 2145-2148.

19. Tejero, T.; Franco, S.; Junquera, F.; Lanaspa, A.; Merchan, F.L.; Merino, P.; Rojo, I. Tetrahedron: Asymmetry 1996, 7, 667-670.

20. (a) Merino, P.; Merchan, F.L.; Tejero, T. Acta Cryst. Sect. C. 1995, 51, 2400-2402. (b) Merino, P.; Junquera, F.; Merchan, F.L.; Tejero, T. Acta Cryst. Sect. C. 1996, 52, 3197-3198. (c) Merino, P.; Franco, S.; Junquera, F.; Merchan, F.L.; Tejero, T. Zeits. Krist. 1997, 212, 321-322. (d) Merino, P.; Franco, S.; Merchan, F.L.; Tejero, T. Zeits. Krist. 1998, 213, 133-134. (e) Merino, P.; Franco, S.; Merchan, F.L.; Tejero, T. Zeits. Krist. 1998, 213, 135-136.

21. (a) Lipshutz, B.H. Chem. Rev. 1986, 86, 795-819. (b) Shipman, M. Contemp. Org. Synth. 1995, 2, 1-18. (c) Padwa, A. In Progress in Heterocyclic Chemistry, Suschitzky, H.; Scriven, E.F.V. (Eds.), Pergamon, Oxford, Vol. 6, 1994, pp. 36-55. (d) Novel Applications of Heterocycles in Synthesis, Tetrahedron Symposia-in-Print number 59, Katritzky, A.R. (Ed.), 1996, vol. 52, No. 9.

22. Dondoni, A.; Junquera, F.; Merchan, F.L.; Merino, P.; Tejero, T. Tetrahedron Lett. 1992, 33, 4221-4224.

23. Dondoni, A.; Franco, S.; Merchan, F.L.; Merino, P.; Tejero, T. Synlett 1993, 78-80.

24. Dondoni, A.; Junquera, F.; Merchan, F.L.; Merino, P.; Scherrmann, M.-C.; Tejero, T. J. Org. Chem. 1997, 62, 5484-5496. 
25. Dondoni, A.; Junquera, F.; Merchan, F.L.; Tejero, T. Chem. Commun. 1995, 2127-2128.

26. Dondoni, A.; Franco, S.; Junquera, F.; Merchan, F.L.; Merino, P.; Tejero, T. J. Org. Chem. 1997, 60, 5497-5507.

27. Dondoni, A.; Junquera, F.; Merchan, F.L.; Merino, P.; Tejero, T. Tetrahedron Lett. 1994, 35, 9439-9442 and references cited therein.

Samples Availability: Available from the authors.

(C) 1999 by the authors. Reproduction of this article, by any means, is permitted for noncommercial purposes. 